\title{
Lung Cancer in India: A Scientometric Study of Publications during 2005-14
}

\author{
Ritu Gupta*, K. K. Mueen Ahmed ${ }^{* *}$, B. M. Gupta***, and Madhu Bansal****
}

Ritu Gupta ${ }^{1}$, K. K. Mueen Ahmed ${ }^{2}$, B. M. Gupta ${ }^{3}$, and Madhu Bansal ${ }^{4}$

\section{${ }^{1}$ Formerly with Sri Venkateshwara University, Tirupati 517502 (Present Address: 1 K/A Arjun Nagar, Safdarjang Enclave, New Delhi 110029) ritu7648@gmail.com \\ ${ }^{2}$ Phcog.Net, Buddha Vihar Road, Cox Town, Bengaluru, India 560005 \\ ${ }^{3} 1173$ Sector 15, Panchkula 134113, Haryana \\ ${ }^{4}$ Punjab University, Department of Mathematics Library, Chandigarh 160014 \\ bmgupta1@yahoo.com \\ madhu@pu.ac.in \\ Correspondence \\ Dr. Mueen Ahmed K.K}

No. 17, II Floor, Buddha Vihar Road, Cox Town, Bangalore, INDIA

Phone no: 080-65650760

Email: journals@phcog.net

\section{History}

- Submission Date: 11-06-2016;

- Review completed: 31-08-2016;

- Accepted Date: 12-09-2016.

DOI : 10.5530/ijmedph.2016.4.11

Article Available online

http://www.ijmedph.org/v6/i4

\section{Copyright}

(C) 2016 Phcog.Net. This is an open-access article distributed under the terms of the Creative Commons Attribution 4.0 International license.

\begin{abstract}
This paper examines 3,653 Indian publications on lung cancer research, as covered in Scopus database during 2005-14, experiencing an annual average growth rate of $18.81 \%$ and citation impact of 4.20 . The world lung cancer output $(169,352$ publications) came from several countries, of which the top 15 most productive countries (United States, China, Germany, Japan, United Kingdom, Italy, France, Canada, and South Korea) accounted for $93.17 \%$ share of the global output during 2005-14. India's global publication share was $2.16 \%$ and holds 12 th rank in the global output during 2005-14. India's share of international collaborative publications on lung cancer was $17.79 \%$ during 2005-14, which decreased from 19.89 to $17.06 \%$ from 2005-09 to 2010-14. Breast cancer in the field of medicine accounted for the largest share $(63.62 \%)$ of output, followed by biochemistry, genetics and molecular biology (28.77\%); pharmacology, toxicology, and pharmaceutics $(23.87 \%)$; chemistry (9.31\%); agricultural and biological sciences (3.26\%); and immunology and microbiology $(2.23 \%)$ during 2005-14. Diagnosis, chemotherapy, surgery, and radiotherapy among treatments methods together accounted for a share of $61.20 \%$ publications in Indian lung cancer research during 2005-14. Among the different states, Maharashtra, Delhi, Karnataka, Chandigarh, and Telangana together account for 53.41\% share during 2005-14. In India's cumulative lung cancer publications output during 2005-14, the most productive 14 Indian organizations, 15 authors, and 15 journals together contributed to $33.71,11.27$, and $20.23 \%$ share, respectively. The 31 high-cited papers in lung cancer research registered an average citation per paper of 294.74. Of the 31 high-cited papers (19 articles and 12 reviews), 7 were single institution, 3 national collaborative, and 21 international collaborative papers. The 31 high-cited papers have appeared in 23 journals. In light of this, the authors suggest the need to develop a National Cancer Prevention Policy, which should make specific recommendations for national action by governments and non-government organizations, including programs and strategies, to reduce the incidence of specific preventable cancer types. Keywords: Iung cancer, publications, India, scientometrics, bibliometrics
\end{abstract}

\section{INTRODUCTION}

The lungs are a pair of sponge-like cone-shaped organs in the chest, which are a part of our respiratory system. The left lung is smaller because the heart occupies space on the left side. Furthermore, the lungs are slightly different on each side; the right lung has three lobes, whereas the left lung has two lobes. The lungs are covered by a thin membranous covering called "pleura," which protects and helps the lungs to move back and forth as they expand and contract during breathing. A thin, dome-shaped muscle below the lungs, called "diaphragm," separates the chest from the abdomen. The diaphragm moves up and down during breathing forcing air in and out of the lungs. Main function of the lungs is to exchange gases between the air we breathe and the blood. When we breathe in (inhale), oxygen enters into our body through the lungs and when we breathe out (exhale) carbon dioxide is sent out of our body. Air enters the lungs through the nose or mouth via windpipe (trachea), which divides into the right and left lungs. These airways are called "bronchi" (singular, bronchus). Inside each lung, the bronchus divides into smaller tubes, the "secondary bronchi," which further subdivide into smaller branches called bronchioles. At the end of the bronchioles are tiny air sacs known as "alveoli," which receives many tiny blood vessels. These tiny alveoli perform the function of exchange of gases. ${ }^{1}$

The vast majority (85\%) of cases of lung cancer are due to long-term exposure to tobacco smoke. About $10-15 \%$ of the cases occur in people who have never smoked. These cases are often caused by a combination of genetic factors and exposure to radon gas, asbestos, or other forms of air pollutants, including second-hand smoke. Lung cancer may be seen on chest radiographs and computed tomography (CT) scans. Its diagnosis can be confirmed by biopsy, which is usually performed by bronchoscopy or CTguidance. $^{2}$ 
Lung cancer appears to arise in the bronchi in response to repetitive carcinogenic stimuli, inflammation, and irritation. Disruption of cell development occurs in the mucosal lining and progresses to elevate or erode the basal membrane. The tumor then spreads throughout the lung and will eventually metastasize to the lymph nodes and other parts of the body. There are four main histologic classifications of lung cancer: squamous cell carcinomas, adenocarcinomas, small cell carcinomas, and large cell carcinoma. Because the behavior and management of squamous cell carcinoma, adenocarcinoma, and large cell carcinomas are very similar, they are often grouped together as non-small cell lung cancer (NSCLC) in contrast to small cell lung cancer (SCLC), which has a distinct natural history and management. Squamous cell carcinoma is most commonly found in men and shows the strongest relationship with smoking. It arises in the larger and more central bronchi and tends to spread locally, later metastasizing to other types but grows rapidly at its site of origin. Adenocarcinoma was previously known as the most common type of lung cancer in women and non-smokers; however, the incidence of adenocarcinoma has increased in the last two decades, and it is now the most common histological subtype in both males and females. The reason for the increasing incidence of adenocarcinoma is not well understood, but may be related to changing patterns of smoking. Cell carcinomas are likely to be undifferentiated squamous cell and adenocarcinoma. They usually consist of large polygonal cells with vesicular nucle. ${ }^{3}$

Lung cancer has been the most common cancer in the world for several decades. There are estimated to be 1.8 million new cases in 2012 (12.9\% of the total), of which $58 \%$ occur in developing countries. Lung cancer remains as the most common cancer in men worldwide (1.2 million, $16.7 \%$ of the total), with the highest estimated age-standardized incidence rates in Central and Eastern Europe (53.5 per 100,000) and Eastern Asia (50.4 per 100,000). The low rates are observed in Middle and Western Africa (2.0 and 1.7 per 100,000, respectively). In women, the incidence rates are generally lower, and the geographical pattern is a little different primarily reflecting different historical exposure to tobacco smoking. Thus, the highest estimated rates are in Northern America (33.8\%) and Northern Europe (23.7\%) with a relatively high rate in Eastern Asia (19.2\%) and the lowest rates again in Western and Middle Africa (1.1 and $0.8 \%$, respectively). Lung cancer is the most common cause of death from cancer worldwide, estimated to be responsible for nearly one in five (1.59 million deaths, $19.4 \%$ of the total). Furthermore, the overall ratio of mortality to incidence is $0.87 .^{4}$

According to GLOBOCAN 2012, there were estimated 70,000 new cases (54,000 in men and 17,000 in women) and estimated mortality of 64,000 in 2012 (49,000 in men and 15,000 in women) in India. In India, lung cancer constitutes $6.9 \%$ of all new cancer cases and $9.3 \%$ of all cancer related deaths in both sexes; it is the commonest cancer and cause of cancer-related mortality in men, with the highest reported incidences from Mizoram in both males and females (age-adjusted rate: 28.3 and 28.7 per 100,000 population in males and females, respectively). The time trends of lung cancer show a significant rise in Delhi, Chennai, and Bengaluru in both sexes. The incidence and pattern of lung cancer differ as per geographic region and ethnicity and largely reflect the prevalence and pattern of smoking. The overall 5-year survival rate of lung cancer is dismal with approximately $15 \%$ in developed countries and 5\% in developing countries 3 . Screening by low-dose computed tomography (CT) in high-risk population demonstrated a relative risk reduction of $20 \%$ in lung cancer mortality but with a false positive rate of $96 \%$. In India, where tuberculosis is prevalent, the applicability of such screening tool is questionable. Development of newer non-invasive methods/biomarkers for early diagnosis and screening of high-risk population is warranted. ${ }^{5}$

\section{Literature Review}

Ho, Satoh, and $\operatorname{Lin}^{6}$ explored a bibliometric approach to quantitatively assess research trends in lung cancer in Japan using the Science Citation Index (SCI) database of lung cancer from 1991 to 2008. They analyzed the articles by the scientific output and research performances of individuals, institutions, and collaborative countries with Japan. They applied distribution of words in the article title, author keywords, and Keywords Plus in different periods to evaluate research trends by the frequency of keywords used. Their analysis indicated a strategy to connect molecular biology with clinical practice. Ho, Nakazawa, Sato, Tamura, Kurishma, and Satoh ${ }^{7}$ explored a bibliometric approach to quantitatively assess research trends in cisplatincontaining chemotherapy for SCLC using related literature in the SCI expanded database from 1992 to 2011. They analyzed the articles by the scientific output and research performances of countries and institutions. Chitra, Jeyshankar, and $\mathrm{Abu}^{8}$ examined the research output of lung cancer in the G7 and in Brazil, Russia, India, and China (BRIC countries) using scientometric data by obtaining from Scopus database on lung cancer during 2003-12. They compared the compound annual growth rate (CAGR), collaboration coefficient (CC), and publication activity using transformative activity index (TAI) of both G7 and BRIC countries. They adopted two relative indicators-absolute citation impact (ACI) and relative citation impact (RCI) to compare the quality and impact of the lung cancer research.

\section{Objectives}

In this study, our main objectives were to study the performance of Indian research in lung cancer during 2005-14, based on publications covered in Scopus database. In particular, following were the study objectives: (i) to study the growth of world and Indian research output and the citation pattern of the Indian research output; (ii) to study the global publication share of top 15 most productive countries and the place of India in global output; (iii) to study the international collaboration share of Indian publications and the contribution of leading foreign countries in India's collaborative output; (iv) to study the distribution of Indian research output by broad subject areas and study their growth and decline; (v) to study the Indian lung cancer output by treatment methods and their distribution by geographical areas; (vi) to study the publication productivity and citation impact of 15 most productive organizations and authors; (vii) to study the medium of communication; and (vii) to study the characteristics of high-cited papers.

\section{Methodology}

We retrieved and downloaded the publication data of the world and of 15 most productive countries in lung cancer from the Scopus database (http://www.scopus.com) for 10 years during 2005-14. We used a number of keywords, such as "lung" and "cancer or neoplasm or carcinoma" were used in "title, abstract, and keyword" tag and restricting it to the period 2005-14 in "date range tag" to search the global publication data, which we term as the main search string. When the main search string was used restricted to 15 most productive countries in "country tag," as shown below, the publication data on 15 productive countries were obtained. When the main search string was further restricted to "subject area tag," "country tag," "source title tag," "journal title name," and "affiliation tag," we obtained information on distribution of publications by subject, collaborating countries, and organization. For citation data, the 3-year, 2-year, and 1-year citation window was used for publications during 2005-12, 2013, and 2014. In addition, citations to publications were also collected from date of publication till the end of April 2015. The data for the study was collected in April 2015.

(((TITLE-ABS-KEY (lung) AND TITLE-ABS-KEY(cancer or neoplasm or carcinoma)) AND PUBYEAR > 2004 AND PUBYEAR < 2015) AND 
TITLE-ABS-KEY(cancer or neoplasm or carcinoma)) AND PUBYEAR $>2004$ AND PUBYEAR < 2015))

(((TITLE-ABS-KEY (lung) AND TITLE-ABS-KEY(cancer or neoplasm or carcinoma)) AND PUBYEAR > 2004 AND PUBYEAR < 2015) AND TITLE-ABS-KEY(cancer or neoplasm or carcinoma)) AND PUBYEAR > 2004 AND PUBYEAR < 2015)) AND (LIMIT-TO (AFFILCOUNTRY,"India”))

\section{Analysis}

The world and India published 169,352 and 3,653 publications on lung cancer during 2005-14, which increased respectively from 12,476 and 143 in 2005 to 18,947 and 630 in 2014, registering an annual average growth rate of 5.00 and $18.81 \%$, respectively. The cumulative growth of world and Indian publications in lung cancer has increased respectively from 71,127 and 945 during 2005-09 to 98,225 and 2,708 during $2010-14$, witnessing a growth rate of 38.10 and $186.57 \%$, respectively. Of the India's total publications in lung cancer, $71.83 \%(2,624)$ appeared as articles, $15.3 \%$ (559) as reviews, $5.36 \%(196)$ as letters, $3.61 \%(132)$ as conference papers, $1.29 \%(47)$ as notes, $0.98 \%$ (36) as editorials, $0.66 \%$ (24) as articles in press, $0.55 \%$ (20) as short surveys, $0.27 \%$ (10) as book chapters, $0.05 \%$ (2) as erratum, and $0.027 \%$ (1) as book during 2005-14. India's share of global publications in lung cancer was $2.16 \%$ during 2005-14, which increased from $1.33 \%$ during $2005-09$ to $2.76 \%$ during 2010-14. The average citation per publication registered by Indian publications in lung cancer was 4.20 during 2005-14, which decreased from 4.29 during 2005-09 to 4.17 during 2010-14 (Table 1).

\section{Global Publication Share and Citation Impact of Top 15 Most Productive Countries}

The global research output in lung cancer originated in more than 100 countries during 2005-14. Table 2 lists the output of top 15 most productive countries in lung cancer that produced $93.17 \%$ of the global output during 2005-14, which increased from 89.50\% during 2005-09 to $95.84 \%$ during $2010-14$. The publication share of 15 most productive countries in lung cancer varied from 1.69 to $30.29 \%$ during 2005-14, with highest publication share (30.29\%) coming from United States, followed by China (11.19\%); Japan (10.03\%); United Kingdom (5.92\%); Germany (5.63\%); Italy (5.50\%); Canada, France, and Japan (from 4.04 to $4.48 \%$ ); Spain, Australia, Netherlands, India, and South Korea (from 2.49 to $2.80 \%$ ); and Sweden and Switzerland (from 1.51 to $1.71 \%$, respectively) during $2005-14$. The global publication share has increased by $6.61 \%$ in China, followed by India (1.43\%), South Korea (0.89\%), Australia $(0.44 \%)$, Taiwan $(0.38 \%)$, Canada $(0.16 \%)$, Netherlands $(0.04 \%)$, and Turkey $(0.01 \%)$, as against decrease by $1.91 \%$ in the United States, followed by Germany (0.56\%), United Kingdom (0.48\%), France $(0.24 \%)$, Spain $(0.21 \%)$, Italy $(0.20 \%)$, Canada $(0.16 \%)$, and Japan $(0.01 \%)$ from 2005-08 to 2009-14 (Table 2).

\section{International Collaboration}

India's share of international collaborative publications in lung cancer research output was $17.79 \%$ during $2005-14$, which decreased from $19.89 \%$ during $2005-09$ to $17.06 \%$ during $2010-14$. India has collaborated with several countries in lung cancer research during 2005-14. Among the collaborating countries, the largest share (51.69\%) was contributed by the United States, followed by United Kingdom (10.77\%), France (10.46\%), Germany (10.31\%), Italy and Australia (7.23\% each), Japan (6.92\%), China and Canada (5.85\% each), and South Korea (5.69\%) during 2005-14. The international collaborative publication share of foreign countries in India's publication output increased by $4.99 \%$ in France, followed by United States (3.88\%), Germany (1.78\%), Australia (1.19\%), China (0.74\%), and Italy (0.44), as against decrease by $2.20 \%$ in Japan, followed by South Korea (1.72\%), United Kingdom (1.30\%), and Canada (0.01\%) from 2005-09 to 2010-14 (Table 3).

\section{Subject-wise Distribution of Research Output}

India's lung cancer research output during 2005-14 has been published in the context of six subfields (as reflected in Scopus database classification), with highest publication share (63.62\%) coming from medicine; followed by biochemistry, genetics, and molecular biology $(28.77 \%)$; pharmacology, toxicology, and pharmaceutics (23.87\%); chemistry (9.31\%); agricultural and biological sciences (3.26\% share); and immunology and microbiology (2.23\%). The research activity, as reflected in activity index, has witnessed increase in pharmacology, toxicology, and pharmaceutics (from 68.27 to 111.27); chemistry (from 57.98 to 114.66); and agricultural and biological sciences (from 87.71 to 104.29) in contrast to decrease in medicine (from 111.44 to 96.01); biochemistry, genetics, and molecular biology (from 104.0 to 95.30); and immunology and microbiology (from $104.46 \%$ to 98.44 ) from $2005-09$ to $2010-14$. Among these six subjects, the largest citation impact per publication (5.15 and 5.09) was registered by chemistry and biochemistry, genetics and molecular biology, followed by pharmacology, toxicology, and pharmaceutics (4.99); agricultural and biological; sciences (4.88); immunology and microbiology (4.87); and medicine (2.77) during 2005-14 (Table 4).

\section{Type of Lung Cancer}

Lung cancer may be classified into four main groups: NSCLC (85\%), SCLC (15\%), mesothelioma, and carcinoid cancers. NSCLC is further divided into three major subgroups: adenocarcinoma, squamous cell carcinoma, and a less well-characterized group "large cell carcinoma" $(40,30$, and $15 \%$ of all lung cancer cases, respectively). As expected, the largest publication share $(28.90 \%)$ was contributed by as NSCLC, followed by SCLC (20.0\%), mesothelioma (5.39\%), and carcinoid tumors (0.99\%) during 2005-14. The publication share increased in NSCLC (from 26.14\%to 29.80\%) and SCLC (from 17.35 to 20.9\%), but decreased in mesothelioma (from 4.13 to $2.58 \%$ ), and carcinoid tumors (from 1.38 to $0.85 \%$ ) from $2005-09$ to $2010-14$ (Table 5).

\section{Distribution of Publications by Treatment Methods}

In terms of treatment methods used in lung cancer research in India during 2005-14, the largest publication share (20.5\%) was registered by diagnosis, followed by chemotherapy (18.20\%), surgery $(11.20 \%)$, radiotherapy $(10.90 \%)$, screening $(8.73 \%)$, prognosis $(8.08 \%)$, pathology (7.80\%), genetics $(2.27 \%)$, quality of life (2.27\%), epidemiology (1.64\%), and palliative care $(1.23 \%)$ during $2004-13$. The top five treatment methods together account for $56.26 \%$ share of the total publication output on lung cancer during 2005-14. The publication share has increased by $3.79 \%$ in screening, as against decrease by $4.04 \%$ in pathology, $2.52 \%$ in prognosis, $1.65 \%$ in surgery, $1.6 \%$ in diagnosis, $1.4 \%$ in radiotherapy, $0.91 \%$ in palliative care, $0.60 \%$ in chemotherapy, $0.36 \%$ in genetics, $0.08 \%$ in quality of life, and $0.07 \%$ in epidemiology from $2005-09$ to 2010-14 (Table 6).

\section{Distribution of Research Output by Geographical Areas}

Among Indian states and union territories contributing to lung cancer research during 2005-14, the largest publication share $(16.07 \%)$ came from Maharashtra, followed by Delhi (15.93\%), Karnataka (8.65\%), Chandigarh (6.65\%), Telangana (6.10\%), Tamil Nadu (4.38\%), Kerala (4.35\%), West Bengal (2.87\%), Uttar Pradesh (2.52\%), Punjab (2.35\%), Haryana (2.24\%), Rajasthan (2.08\%), Orissa (0.49\%), Madhya Pradesh $(0.46 \%)$, and Bihar $(0.22 \%)$ during 2005-14. Together the first five states account for $53.41 \%$ share of the Indian output in lung cancer during 2005-14. The share of lung cancer publications have increased in 
Table 1: World and Indian Literature in Lung Cancer: Growth, Citation Impact, and International Collaboration, 2005-14

\begin{tabular}{cccccccc}
\hline $\begin{array}{c}\text { Publication } \\
\text { Year }\end{array}$ & World & \multicolumn{7}{c}{ India } \\
\cline { 2 - 8 } & TP & TP & TC & ACPP & ICP & \%ICP & $\begin{array}{c}\text { Global } \\
\text { Share }\end{array}$ \\
\hline 2005 & 12,476 & 143 & 649 & 4.54 & 35 & 24.48 & 1.15 \\
2006 & 13,216 & 141 & 551 & 3.91 & 25 & 17.73 & 1.07 \\
2007 & 13,939 & 186 & 661 & 3.55 & 29 & 15.59 & 1.33 \\
2008 & 14,894 & 211 & 970 & 4.6 & 41 & 19.43 & 1.42 \\
2009 & 16,602 & 264 & 1,221 & 4.63 & 58 & 21.97 & 1.59 \\
2010 & 17,654 & 352 & 1,854 & 5.27 & 53 & 15.06 & 1.99 \\
2011 & 18,906 & 497 & 2,618 & 5.27 & 85 & 17.1 & 2.63 \\
2012 & 20,812 & 582 & 4,558 & 7.83 & 92 & 15.81 & 2.8 \\
2013 & 21,906 & 647 & 1,825 & 2.82 & 102 & 15.77 & 2.95 \\
2014 & 18,947 & 630 & 430 & 0.68 & 130 & 20.63 & 3.33 \\
$2005-09$ & 71,127 & 945 & 4,052 & 4.29 & 188 & 19.89 & 1.33 \\
$2010-14$ & 98,225 & 2708 & 11,285 & 4.17 & 462 & 17.06 & 2.76 \\
$2005-14$ & 169,352 & 3,653 & 15,337 & 4.20 & 650 & 17.79 & 2.16 \\
\hline
\end{tabular}

TP $=$ Total Papers, $\mathrm{TC}=$ Total Citations; $\mathrm{ACPP}=$ Average Citations Per Paper; ICP = International Collaborative Papers

Table 2: Publication Output and Global Publication Share of Top 15 Most Productive Countries in Lung Cancer, 2005-14

\begin{tabular}{|c|c|c|c|c|c|c|}
\hline \multirow[t]{2}{*}{ Country Name } & \multicolumn{3}{|c|}{ Number of Publications } & \multicolumn{3}{|c|}{ Global Share of Publications } \\
\hline & 2005-09 & 2010-14 & 2005-14 & 2005-09 & 2010-14 & 2005-14 \\
\hline United States & 22,336 & 28,963 & 51,299 & 31.4 & 29.49 & 30.29 \\
\hline China & 5,236 & 13,720 & 18,956 & 7.361 & 13.97 & 11.19 \\
\hline Japan & 7,131 & 9,847 & 16,978 & 10.03 & 10.02 & 10.03 \\
\hline United Kingdom & 4,412 & 5,619 & 10,031 & 6.203 & 5.721 & 5.92 \\
\hline Germany & 4,236 & 5,299 & 9,535 & 5.956 & 5.395 & 5.63 \\
\hline Italy & 3,993 & 5,316 & 9,309 & 5.614 & 5.412 & 5.50 \\
\hline France & 3,290 & 4,303 & 7,593 & 4.626 & 4.381 & 4.48 \\
\hline Canada & 2,381 & 3,451 & 5,832 & 3.348 & 3.513 & 3.44 \\
\hline South Korea & 1,921 & 3,528 & 5,449 & 2.701 & 3.592 & 3.22 \\
\hline Spain & 2,277 & 2,934 & 5,211 & 3.201 & 2.987 & 3.08 \\
\hline Netherlands & 1,704 & 2,396 & 4,100 & 2.396 & 2.439 & 2.42 \\
\hline India & 945 & 2,708 & 3,653 & 1.329 & 2.757 & 2.16 \\
\hline Taiwan & 1,318 & 2,194 & 3,512 & 1.853 & 2.234 & 2.07 \\
\hline Australia & 1,270 & 2,188 & 3,458 & 1.786 & 2.228 & 2.04 \\
\hline Turkey & 1,200 & 1,670 & 2,870 & 1.687 & 1.7 & 1.69 \\
\hline World & 71,127 & 98,225 & 16,9352 & 100 & 100 & 100 \\
\hline
\end{tabular}

Telangana (2.67\%), West Bengal (1.88\%), Uttar Pradesh (1.68\%), Karnataka (1.39\%), Haryana (1.17\%), Punjab (0.75\%), Madhya Pradesh (0.49\%), Tamil Nadu (0.48\%), Orissa $(0.38 \%)$, and Bihar $(0.15 \%)$, as against decrease in Delhi (5.06\%), Maharashtra (3.59\%), Chandigarh (2.73\%), Kerala (0.98\%), and Rajasthan (0.76\%) from 2005-09 to 2010-14 (Table 7).

\section{Profile of Top 14 Most Productive Organizations}

The productivity of 14 most productive Indian organizations in lung cancer varied from 35 to 267 publications, which together contributed
$33.71 \%$ (1201 publications) share in the cumulative publications output of India in lung cancer research during 2005-14. Table 8 presents the scientometric profile of these 14 Indian organizations. Seven organizations have registered higher publications output than the group average of 85.79\%: Tata Memorial Hospital, Mumbai (267 publications); All India Institute of Medical Sciences, New Delhi (210 publications); Postgraduate Institute of Medical Education and Research, Chandigarh (159 publications); Indian Institute of Chemical Technology, Hyderabad (88 publications); University of Madras (112 publications); Indian Institute of Chemical Technology (IICT), Hyderabad (110 publications); and 
Table 3: Share of Leading Countries in India's International Collaborative Output in Lung Cancer during 2005-14

\begin{tabular}{|c|c|c|c|c|c|c|}
\hline \multirow[t]{2}{*}{ Country Name } & \multicolumn{3}{|c|}{ Number of Papers } & \multicolumn{3}{|c|}{ Share of Papers } \\
\hline & 2005-09 & 2010-14 & 2005-14 & 2005-09 & 2010-14 & 2005-14 \\
\hline United States & 92 & 244 & 336 & 48.94 & 52.81 & 51.69 \\
\hline United Kingdom & 22 & 48 & 70 & 11.7 & 10.39 & 10.77 \\
\hline France & 13 & 55 & 68 & 6.91 & 11.9 & 10.46 \\
\hline Germany & 17 & 50 & 67 & 9.04 & 10.82 & 10.31 \\
\hline Italy & 13 & 34 & 47 & 6.91 & 7.36 & 7.231 \\
\hline Australia & 12 & 35 & 47 & 6.38 & 7.58 & 7.231 \\
\hline Japan & 16 & 29 & 45 & 8.51 & 6.28 & 6.923 \\
\hline China & 10 & 28 & 38 & 5.32 & 6.06 & 5.846 \\
\hline Canada & 11 & 27 & 38 & 5.85 & 5.84 & 5.846 \\
\hline South Korea & 13 & 24 & 37 & 6.91 & 5.19 & 5.692 \\
\hline Total of the Country & 188 & 462 & 650 & 100 & & \\
\hline
\end{tabular}

Table 4: Subject-wise Break-up of India's Publications in Lung Cancer, 2005-14

\begin{tabular}{|c|c|c|c|c|c|c|c|c|c|c|}
\hline \multirow[t]{2}{*}{ Broad Subject* } & \multicolumn{3}{|c|}{ Number of Papers } & \multicolumn{7}{|c|}{ 2005-14 } \\
\hline & 2005-09 & 2010-14 & 2005-14 & TC & ACPP & $\mathrm{HI}$ & ICP & \%ICP & HCP & $\% \mathrm{HCP}$ \\
\hline Medicine & 670 & 1654 & 2324 & 6439 & 2.77 & 48 & 401 & 17.3 & 24 & 1.03 \\
\hline $\begin{array}{c}\text { Biochemistry, Genetics, \& Molecular } \\
\text { Biology }\end{array}$ & 284 & 767 & 1051 & 5350 & 5.09 & 46 & 261 & 24.8 & 5 & 0.48 \\
\hline $\begin{array}{c}\text { Pharmacology, Toxicology, \& } \\
\text { Pharmaceutics }\end{array}$ & 154 & 718 & 872 & 4347 & 4.99 & 41 & 147 & 16.9 & 9 & 1.03 \\
\hline Chemistry & 51 & 289 & 340 & 1752 & 5.15 & 29 & 85 & 25 & 0 & 0 \\
\hline Agricultural \& Biological Sciences & 27 & 92 & 119 & 581 & 4.88 & 16 & 28 & 23.5 & 2 & 1.68 \\
\hline Immunology \& Microbiology & 22 & 63 & 85 & 414 & 4.87 & 13 & 14 & 16.5 & 0 & 0 \\
\hline Total of the Country & 945 & 2708 & 3653 & & & & & & & \\
\hline
\end{tabular}

TP = Total Papers, $\mathrm{TC}=$ Total Citations; ACPP = Average Citations Per Paper; ICP = International Collaborative Papers; HI = h-index; HCP = High Cited Papers

*There is a duplication of papers under the various subjects, because of overlapping of journals covered

Table 5: Distribution of Publications by Type of Lung Cancer during 2005-14

\begin{tabular}{cccccccc}
\hline Type of Lung Cancer & \multicolumn{3}{c}{ Number of Papers } & \multicolumn{4}{c}{ Share of Papers } \\
\cline { 2 - 7 } & $2005-09$ & $2010-14$ & $2005-14$ & $2005-09$ & $2010-14$ & $2005-14$ \\
\hline Non-Small Cell Lung Cancer & 247 & 808 & 1,055 & 26.14 & 29.8 & 28.9 \\
Small Cell Lung Cancer & 164 & 565 & 729 & 17.35 & 20.9 & 20.0 & 8.6 \\
Squamous Cell Carcinoma & 72 & 242 & 314 & 7.62 & 8.94 & 12.3 & 11.5 \\
Adenocarcinoma & 86 & 334 & 420 & 9.10 & 3.28 & 2.33 & 2.57 \\
Large Cell Carcinoma & 31 & 63 & 94 & 4.13 & 2.58 & 5.39 \\
Mesothelioma & 39 & 70 & 197 & 1.38 & 0.85 & 0.99 \\
Carcinoid Tumors & 13 & 23 & 36 & & & \\
Total of the Country & 945 & 2,708 & 3,653 & & &
\end{tabular}

Postgraduate Institute of Medical Education and Research (PGIMER), Chandigarh during 2005-14. Three organizations have registered more than the average citation per publication (6.29) among the 15 organizations during 2004-15: Sanjay Gandhi Postgraduate Institute of Medical Sciences (SGPIMS), Lucknow (44.50); All India Institute of Medical Sciences (AIIMS), Delhi (9.054); and National Institute of Pharmaceutical Education and Research (NIPER), Mohali (6.33) during 2005-14. Seven organizations have registered more than the average h-index (12.07) of all 14 organizations: Tata Memorial Centre (TMC), Mumbai (23); All India Institute of Medical Sciences (AIIMS), Delhi (19); Indian Institute of Chemical Technology (IICT), Hyderabad (16); University of Madras and Postgraduate Institute of Medical Sciences (PGIMER), Chandigarh (15 each); and Indian Institute of Integrated Medicine (IIIM), Srinagar (13) during 2005-14. Seven organizations have achieved more than the average share of international collaborative publications $(14.90 \%)$ of all organizations: Christian Medical College (CMC), Vellore (29.17\%); 
Table 6: Distribution of India's Lung Cancer Publications by Treatment Methods, 2005-14

\begin{tabular}{ccccccc}
\hline \multirow{2}{*}{$\begin{array}{c}\text { Treatment } \\
\text { Methods }\end{array}$} & \multicolumn{3}{c}{ Number of Publications } & \multicolumn{3}{c}{ Share of Publications } \\
\cline { 2 - 7 } & $2005-09$ & $2010-14$ & $2005-09$ & $2010-14$ & $2005-09$ & $2010-14$ \\
\hline Diagnosis & 205 & 544 & 749 & 21.7 & 20.1 & 20.5 \\
Chemotherapy & 176 & 488 & 664 & 18.6 & 18.0 & 18.2 \\
Surgery & 121 & 302 & 423 & 12.8 & 11.2 & 11.6 \\
Radiotherapy & 113 & 286 & 399 & 12.0 & 10.6 & 10.9 \\
Screening & 56 & 263 & 319 & 5.93 & 9.71 & 8.73 \\
Prognosis & 94 & 201 & 295 & 9.95 & 7.42 & 8.08 \\
Pathology & 102 & 183 & 285 & 10.8 & 6.76 & 7.80 \\
Genetics & 24 & 59 & 83 & 2.54 & 2.18 & 2.27 \\
Quality of Life & 22 & 61 & 83 & 2.33 & 2.25 & 2.27 \\
Epidemiology & 16 & 44 & 60 & 1.69 & 1.62 & 1.64 \\
Palliative Care & 18 & 27 & 45 & 1.9 & 1 & 1.23 \\
& 945 & 2,708 & 3,653 & & & \\
\hline
\end{tabular}

Table 7: Geographical Distribution of Lung Cancer Research Publications in India, 2005-14

\begin{tabular}{ccccccc}
\hline Name of & \multicolumn{3}{c}{ Number of Publications } & \multicolumn{3}{c}{ Share of Publications } \\
\cline { 2 - 7 } Geographical Area & $2005-09$ & $2010-14$ & $2005-09$ & $2010-14$ & $2005-09$ & $2010-14$ \\
\hline Maharashtra & 177 & 410 & 587 & 18.7 & 15.1 & 16.07 \\
Delhi & 186 & 396 & 582 & 19.7 & 14.6 & 15.93 \\
Karnataka & 72 & 244 & 316 & 7.62 & 9.01 & 8.65 \\
Chandigarh & 82 & 161 & 243 & 8.68 & 5.95 & 6.65 \\
Telangana & 39 & 184 & 223 & 4.13 & 6.79 & 6.10 \\
Tamil Nadu & 38 & 122 & 160 & 4.02 & 4.51 & 4.38 \\
Kerala & 48 & 111 & 159 & 5.08 & 4.1 & 4.35 \\
West Bengal & 14 & 91 & 105 & 1.48 & 3.36 & 2.87 \\
Uttar Pradesh & 12 & 80 & 92 & 1.27 & 2.95 & 2.52 \\
Punjab & 17 & 69 & 86 & 1.8 & 2.55 & 2.35 \\
Haryana & 13 & 69 & 82 & 1.38 & 2.55 & 2.24 \\
Rajasthan & 25 & 51 & 76 & 2.65 & 1.88 & 2.08 \\
Orissa & 2 & 16 & 18 & 0.21 & 0.59 & 0.49 \\
Madhya Pradesh & 1 & 16 & 17 & 0.11 & 0.59 & 0.46 \\
Bihar & 1 & 7 & 8 & 0.11 & 0.26 & 0.22 \\
Total of the Country & 945 & 2,708 & 3,653 & & & \\
\hline
\end{tabular}

Bhabha Atomic Research Centre (BARC), Mumbai (28.57\%); National Institute of Pharmaceutical Education and Research (NIPER), Mohali (22.5\%); Tata Memorial Centre (TMC), Mumbai (22.47\%); Punjab University, Chandigarh (17.86\%); Sanjay Gandhi Postgraduate Institute of Medical Sciences (SGPIMS), Lucknow (17.14\%); and Indian Institute of Chemical Technology (IICT), Hyderabad (15.91\%) during 2005-14.

\section{Profile of Top 15 Most Productive Authors}

The productivity of 15 most productive Indian authors in lung cancer varied from 21 to 37 publications and together contributed $11.27 \%$ (400 publications) share in the cumulative publications output of India in lung cancer research during 2005-14. Table 9 presents the scientometric profile of these 15 Indian authors. Five authors have registered higher publications output than the group average of 26.67: N. Singh and A. K. Saxena (37 publications each), C. S. Pramash (33 publications),
K. Sakthise (30 publications), and K. Prabhash (27 publications) during 2005-14. Six authors have registered more than the average citation per publication (3.05) among all 15 authors. Seven authors have registered more than the average h-index (7.27) of all 15 organizations during 2004-13: A. Kamal, A. K. Saxena, R. Guleria, A. Mohan, and K. Sakthise (10 each) and D. Behera and T. Devaki (8 each) during 2005-14. Five authors have achieved more than the average share of national collaborative publications (13.00\%) of all authors: S. Basu (50.00\%), C. S. Pramash (27.30\%), A. Kamal (20.80\%), A. Mohan (15.40\%), and K. Prabhash (14.80\%) during 2005-14.

\section{Medium of Communication}

Of the total publications in lung cancer, $97.18 \%(3,550)$ appeared in journals, $1.75 \%$ (64) in conference proceedings, $0.30 \%$ (11) in books, and $0.11 \%$ (4) in trade publications. The 15 most productive journals 
Table 8: Scientometric Profile of Top 14 Most Productive Indian Organizations in Lung Cancer, 2005-14

\begin{tabular}{|c|c|c|c|c|c|c|c|c|c|}
\hline S.No & Name of the Organization & TP & TC & ACPP & $\mathrm{H} 1$ & ICP & $\% \mathrm{ICP}$ & $\mathrm{HCP}$ & $\% \mathrm{HCP}$ \\
\hline 1 & Tata Memorial Centre (TMC), Mumbai & 267 & 1414 & 5.3 & 23 & 60 & 22.47 & 4 & 1.5 \\
\hline 2 & All India Institute of Medical Sciences (AIIMS), Delhi & 210 & 1901 & 9.05 & 19 & 24 & 11.43 & 3 & 1.43 \\
\hline 3 & $\begin{array}{c}\text { Post Graduate Institute of Medical Sciences (PGIMER), } \\
\text { Chandigarh }\end{array}$ & 159 & 368 & 2.31 & 15 & 12 & 7.547 & 0 & 0 \\
\hline 4 & $\begin{array}{c}\text { Indian Institute of Chemical Technology (IICT), } \\
\text { Hyderabad }\end{array}$ & 88 & 433 & 4.92 & 16 & 14 & 15.91 & 0 & 0 \\
\hline 5 & University of Madras & 77 & 261 & 3.39 & 15 & 10 & 12.99 & 0 & 0 \\
\hline 6 & Indian Institute of Integrated Medicine (IIIM), Srinagar & 61 & 285 & 4.67 & 13 & 3 & 4.918 & 0 & 0 \\
\hline 7 & Punjab University, Chandigarh & 56 & 222 & 3.96 & 10 & 10 & 17.86 & 0 & 0 \\
\hline 8 & Christian Medical College (CMC), Vellore & 48 & 247 & 5.15 & 8 & 14 & 29.17 & 1 & 2.08 \\
\hline 9 & Institute of Rotary Cancer Hospital (IRCH), Delhi & 48 & 269 & 5.6 & 8 & 4 & 8.333 & 1 & 2.08 \\
\hline 10 & CSM Medical University, Lucknow & 42 & 137 & 3.26 & 5 & 1 & 2.381 & 1 & 2.38 \\
\hline 11 & $\begin{array}{c}\text { National Institute of Pharmaceutical Education \& } \\
\text { Research (NIPER), Mohali }\end{array}$ & 40 & 253 & 6.33 & 12 & 9 & 22.5 & 1 & 2.5 \\
\hline 12 & $\begin{array}{c}\text { Sher-I-Kashmir Institute of Medical Sciences (SKIMS), } \\
\text { Srinagar }\end{array}$ & 35 & 79 & 2.26 & 7 & 2 & 5.714 & 0 & 0 \\
\hline 13 & $\begin{array}{l}\text { Sanjay Gandhi Postgraduate Institute of Medical } \\
\text { Sciences (SGPIMS), Lucknow }\end{array}$ & 35 & 1,556 & 44.5 & 8 & 6 & 17.14 & 2 & 5.71 \\
\hline \multirow[t]{4}{*}{14} & Bhabha Atomic Research Centre (BARC), Mumbai & 35 & 130 & 3.71 & 10 & 10 & 28.57 & 0 & 0 \\
\hline & Total of 14 Organizations & 1,201 & 7,555 & 6.29 & 12.07 & 179 & & 13 & 1.08 \\
\hline & Total of the world & 3563 & & & & & & & \\
\hline & Share of 14 Organizations in World Total & 33.71 & & & & & & & \\
\hline
\end{tabular}

TP = Total Papers, TC = Total Citations; ACPP = Average Citations Per Paper; ICP = International Collaborative Papers; HI = h-index; HCP = High Cited Papers

Table 9: Scientometric Profile of Top 15 Most Productive Indian Authors in Lung Cancer, 2005-14

\begin{tabular}{|c|c|c|c|c|c|c|c|c|}
\hline S.No & Name of the Author & Affiliation of the Author & TP & $\mathrm{TC}$ & ACPP & $\mathrm{HI}$ & ICP & $\%$ ICP \\
\hline 1 & N. Singh & PGIMER-Chandigarh & 37 & 58 & 1.57 & 6 & 0 & 0 \\
\hline 2 & A. K. Saxena & IIIM-Srinagar & 37 & 168 & 4.54 & 10 & 0 & 0 \\
\hline 4 & K. Sakthise & Dr ALM Postgraduate Institute, University of Madras & 30 & 78 & 2.6 & 10 & 4 & 13.3 \\
\hline 5 & K. Prabhash & TMC-Mumbai & 27 & 72 & 2.67 & 5 & 4 & 14.8 \\
\hline 8 & S. Basu & TMC-Mumbai & 26 & 83 & 3.19 & 6 & 13 & 50 \\
\hline 9 & A. N. Aggarwal & PGIMER-Chandigarh & 24 & 63 & 2.63 & 6 & 0 & 0 \\
\hline 10 & A. Kamal & IICT-Hyderabad & 24 & 167 & 6.96 & 10 & 5 & 20.8 \\
\hline 11 & V. Rangarajan & TMC-Mumbai & 23 & 25 & 1.09 & 4 & 0 & 0 \\
\hline \multirow[t]{4}{*}{15} & T. Devaki & University of Madras & 21 & 91 & 4.33 & 8 & 2 & 9.52 \\
\hline & & Total of 15 Authors & 400 & 1218 & 3.05 & 7.27 & 52 & 13.00 \\
\hline & & Total of the Country & 3563 & & & & & \\
\hline & & Share of 15 Authors in Country Output & 11.27 & & & & & \\
\hline
\end{tabular}

TP = Total Papers, TC = Total Citations; ACPP = Average Citations Per Paper; ICP = International Collaborative Papers; HI = h-index; HCP = High Cited Papers 
A scientometric study of lung cancer in India

Table 10: List of Most Productive Journals in Indian in Lung Cancer during 2005-14

\begin{tabular}{ccccc}
\hline \multirow{2}{*}{ S.No } & Name of the Journal & \multicolumn{3}{c}{ Number of Papers } \\
\cline { 3 - 5 } & & $2005-09$ & $2010-14$ & $2005-14$ \\
\hline 1 & Journal of Cancer Research and Therapeutics & 16 & 66 & 82 \\
2 & Asia Pacific Journal of Cancer Prevention & 21 & 60 & 81 \\
3 & Indian Journal of Cancer & 14 & 53 & 67 \\
4 & Lung India & 8 & 56 & 64 \\
5 & European Journal of Medicinal Chemistry & 3 & 56 & 59 \\
6 & Indian Journal of Pathology \& Microbiology & 32 & 25 & 57 \\
7 & Medicinal Chemistry Research & 0 & 47 & 47 \\
8 & BMJ Case Reports & 1 & 40 & 41 \\
10 & Indian Journal of Pharmacy \& Pharmaceutical Science & 0 & 35 & 41 \\
11 & Indian Journal of Medical \& Pediatric Oncology & 2 & 32 & 34 \\
12 & Journal of Clinical \& Diagnostic Research & 0 & 34 & 34 \\
13 & PLOS One & 0 & 33 & 33 \\
14 & Indian Journal of Nuclear Medicine & 0 & 32 & 32 \\
15 & Journal of Indian Medical Association & 8 & 24 & 32 \\
& Total of 15 journals & 111 & 628 & 739 \\
& Total of the country & 945 & 2,708 & 3,653 \\
\hline
\end{tabular}

contributed from 32 to 82 papers and together contributed $20.23 \%$ share (739 papers) to the total journal publication output in lung cancer during 2005-14. The publication share of these top 15 most productive journals increased from 11.75 to $23.19 \%$ from $2005-09$ to $2010-14$. The most productive journals (82 papers) were Journal of Cancer Research and Therapeutics, followed by Asia Pacific Journal of Cancer Prevention (81 papers), Indian Journal of Cancer (67 papers), and Lung India (64 papers) during 2005-14 (Table 10).

\section{High-Cited Papers}

There were 31 high-cited papers (18 papers in citation range of 100-199; 7 papers in 200-299; 1 paper in 400-499; 2 papers in $500-599$; 1 paper each in 600-699, 1000-1099, and 1400-1499) which together received 9,137 citations, accounting for average citation per paper of 294.74. Of the 31 high-cited papers (19 articles and 12 reviews), 7 were single institutional, 3 national collaborative, and 21 international collaborative papers. The 31 high-cited papers have appeared in 23 journals, of which the largest number (7) was published in The Lancet, followed by 2 papers in Nanomedicine, The Lancet Oncology, and New England Journal of Medicine, and 1 paper each in AAPS Journal, Advanced Drug Delivery Reviews, American Journal of Transplantation, Biochemical Pharmacology, Chinese Medicine, Current Drug Delivery, Current Problems in Cancer, Histopathology, International Journal of Epidemiology, Journal of Clinical Biochemistry and Nutrition, Journal of Clinical Oncology, Journal of Controlled Release, Journal of the American College of Surgeons, Journal of Thoracic Oncology, Pharmacological Reports, PLoS One, Science Translational Medicine, Vascular Pharmacology, and World Psychiatry. The 31 high-cited papers involve 37 Indian organizations, of which the highest number of papers (four) are published by Tata Memorial Hospital, Mumbai, followed by three papers by All Indian Institute of Medical Science, New Delhi (3 papers), two papers each by Betty Cowan Research and Innovation Center, Ludhiana; Center for Chronic Disease Control, New Delhi; Institute of Life Sciences, Bhubaneswar; Regional Cancer
Centre, Trivandrum; and Sanjay Gandhi Postgraduate Institute of Medical Sciences, Lucknow. One paper each by Amala Cancer Research Center, Amala Nagar, Thrissur; Annamalai University, Annamalainagar; Associates in Clinical Endocrinology, Education and Research, Chennai; Bharathidasan University, Tiruchirappalli; Birla Institute of Technology and Science, Pilani; C. U. Shah College of Pharmacy and Research, Wadhwan City; Calcutta University, Kolkata; Cancer Institute (WIA), Chennai; CARE Foundation, Banjara Hills, Hyderabad; Christian Medical College, Vellore; Dr. Ambedkar College, Nagpur; MS, Dr. B.C. Roy College of Pharmacy and Allied Health Sciences, Durgapur; GEM Digestive Disease Foundation, GEM Hospital, Coimbatore; Institute of Hematology and Transfusion Medicine, Medical College, Kolkata; Institute Rotary Cancer Hospital, All-India Institute of Medical Sciences, New Delhi; Jadavpur University, Kolkata; Jamia Hamdard, New Delhi; Japanese Society of Transcultural Psychiatry, Medical College, Jaipur; Jawaharlal Nehru Cancer Hospital and Research Center, Bhopal; Medical College, Jaipur; NIPER-Mohali; SAL Hospital and Medical Institute, Ahmedabad; Sekhsaria Institute for Public Health, Mumbai; Sitaram Bhartia Institute of Science and Research, New Delhi; Sterling Hospital, Ahmedabad, University of Delhi; Vector Control Research Centre, Pondicherry; and Voluntary Health Services, Sneha, Chennai.

\section{Summary and Conclusion}

India has contributed 3,653 publications on lung cancer during 2005-14, which has increased from 143 to 630 from 2005 to 2014, registering a growth rate of $18.81 \%$. India's global publication share on lung cancer was $2.16 \%$, which increased from 1.33 to $2.76 \%$ from $2005-09$ to $2010-14$. India registered a citation impact per paper of 4.20 on lung cancer during 2005-14, which decreased from 2.29 to 4.17 from 2005-09 to 2010-14. The global contribution (169,352 papers) contribution on lung cancer during 2005-14 came from more than 100 countries, with largest contribution coming from United States (20.29\%), China (11.19\%), Japan (10.03\%), United Kingdom (9.23\%), Germany (5.63\%), Italy (5.50\%), 
France (4.48\%), Canada (3.44\%), and South Korea (3.22\%). The contribution of top 15 most productive countries on lung cancer together contributed $93.17 \%$ to global share, which has increased from 89.50 to 95.84\% from 2005-09 to 2010-14. The global publication share among the top 15 countries increased in China, India, South Korea, Australia, Taiwan, Canada, Netherlands, and Turkey, as against decrease in United States, Germany, United Kingdom, France, Spain, Italy, Canada, and Japan from 2005-09 to 2010-14. India's share of international collaborative papers on lung cancer was $17.79 \%$ during $2005-14$, which decreased from 19.89 to $17.06 \%$ from $2005-09$ to $2010-14$. Among the major contribution to India's international collaborative output, the largest share $(51.69 \%)$ came from United States, followed by United Kingdom (10.77\%), France (10.46\%), Germany (10.31\%), Italy and Australia (7.23\% each), Japan (6.92\%), China and Canada (5.85\% each), and South Korea (5.69\%) during 2005-14. Medicine, among subjects, contributed the largest publication share (63.62\%), followed by biochemistry, genetics, and molecular biology (28.77\%); pharmacology, toxicology, and pharmaceutics (23.87\%); chemistry (9.31\%); agricultural and biological sciences (3.26\%); and immunology and microbiology (2.23\%). The research activity witnessed increase in pharmacology, toxicology, and pharmaceutics; chemistry; and agricultural and biological sciences in contrast to decrease in medicine, biochemistry, genetics, and molecular biology and immunology and microbiology from 2005-09 to 2010-14. Chemistry and biochemistry registered the largest citation impact per paper (5.15 and 5.09), genetics and molecular biology, followed by pharmacology, toxicology, and pharmaceutics (4.99); agricultural and biological sciences (4.88); immunology and microbiology (4.87); and medicine (2.77) during 2005-14. Among the various types of lung cancers, the largest publication share $(28.90 \%)$ came from NSCLC, followed by SCLC (20.0\%), mesothelioma (5.39\%), and carcinoid tumors (0.99\%) during 2005-14. Diagnosis, Chemotherapy and Surgery together account for $50.3 \%$ share of the total publication output on lung cancer during 2005-14. Maharashtra among Indian states and union territories contributed the largest publication share $(16.07 \%)$, followed by Delhi (15.93\%), Karnataka (8.65\%). Chandigarh (6.65\%), Telangana (6.10\%), Tamil Nadu (4.38\%), Kerala (4.35\%), West Bengal (2.87\%), Uttar Pradesh (2.52\%), Punjab (2.35\%), Haryana (2.24\%), and Rajasthan (2.08\%) during 2005-14. The 14 most productive Indian organizations and 15 authors in lung cancer together respectively contributed 33.71 and $11.27 \%$ to the cumulative India's lung cancer publications output during 2005-14. The 15 most productive journals together contributed $20.23 \%$ to the total journal publication output in lung cancer during 2005-14. In all, there were 31 high-cited papers (18 papers in citation range of 100-199, 7 papers in 200-299, 1 paper in 400-499, 2 papers in 500-599, 1 paper each in 600-699, 1000-1099 and 1400-1499), which together received 9137 citations, accounting for average citation per paper of 294.74. Of the 31 high-cited papers (19 articles and 12 reviews), 7 were single institution papers, 3 national collaborative and 21 international collaborative. The 31 high-cited papers have appeared in 23 journals, of which the largest number (7) was published in The Lancet, followed by 2 papers in Nanomedicine, The Lancet Oncology, and New England Journal of Medicine and 1 paper each in other journals.

The authors suggest the need for developing a National Cancer Prevention Policy, which should make specific recommendations for national action by governments and non-government organizations, including programs and strategies to reduce the incidence of specific preventable cancer types. The authors also suggest the need for increased federal research funding for lung cancer research and ensuring a comprehensive plan of action to increase survival. There is also the need for educating the public about their lung cancer risk and to ensure equitable access to the service; providing guidance to lung cancer screening programs about how to set up and implement responsible, high quality screening programs (meeting these criteria) and encouraging collaborative research for improving early detection in lung cancer and to identify other high-risk populations.

\section{REFERENCES}

1. Institute of Cytology \&Preventive Oncology. Lung cancer. Anatomy and function of lungs. No date. http://cancerindia.org.in/cp/index.php/know-about-cancer/ lung-cancer.

2. Lung cancer. 22 February 2016. https://en.wikipedia.org/wiki/Lung_cancer (Accessed on 23 February 2016)

3. Australia, National Health \& Medical Council. Clinical Practice Guidelines for the prevention, diagnosis and management of lung cancer. 18 March 2004.p.5

4. International Agency for Research on Cancer \&WHO.GLOBOCAN 2012. Estimated Cancer Incidence, Mortality and Prevalence Worldwide in 2012 IARC. 2016. http//globocan.iarc.fr/pages/ fact_sheets_cancer.aspx.

5. Prabhat Singh Malik, Vinod Raina. Lung cancer: Prevalent trends \& emerging concepts (Editorial). Indian J Med Res 141, January 2015, pp 5-7. http://www.icmr. nic.in/ijmr/2015/janaury/editorial2.pdf ; PMid:25857489 PMCid:PMC4405940.

6. Ho, Yuh-Shan, Satoh, Hiroaki and Lin, Shih-Yuan. Japanese lung cancer research trends and performance in Science Citation Index. Internal Medicine 2010;49(20):2219-28. http://dx.doi.org/10.2169/internalmedicine.49.3687; PMid:20962440.

7. Ho, Yuh-Shan, Nakazawa, Kensuke, Sato, Shinya, Tamura, Tomohiro, Kurishma, Koichi and Satoh, Hiroki. Cisplatin for small cell lung cancer: Associated publications in Science Citation Index Expanded. Oncology Letters. 2013;5(2):684-8. PMid:23420619.

8. Chitra V, Jeyshankar R, Abu KS. Lung Cancer Research in G7 and BRIC Countries: A Comparative Analysis by Scientometric Method. International Journal of Advanced Library and Information Science 2014;2(1):72-81. 